\title{
KNOWLEDGE BY NARRATIVES: ON THE METHODOLOGY OF STUMP'S DEFENCE
}

\author{
CHRISTIAN J. FELDBACHER \\ University of Innsbruck
}

Eleonore Stump claims in her book Wandering in Darkness that the problem of evil - better: 'the problem of suffering' - can be solved best by the help of narratives (p. xviii). Narratives are according to her view very important for solving this problem, because they allow one to get a more general view about relevant parts of the discussion of suffering. In this context she distinguishes the more detailed view of the discussion from a more general one by two different modes of cognition: the mode of gathering Dominican knowledge that and the mode of gathering Franciscan knowledge how. Stump thinks that this distinction is crucial for a solution to the problem of suffering:

If we can learn from the narratives the Franciscan knowledge [how], we can then use that knowledge in the (Dominican) philosophical project of formulating a defense and spelling out the nature of a possible morally sufficient reason for God to allow human suffering. (p. 61)

I'm doubting this thesis and will try to argue against it by unfolding a distinction of knowledge that and knowledge how in the sense of Stump (i), summarizing her solution (ii) and showing that within this solution the distinction is not essential (iii).

\section{DOMINICUS VS. FRANCIS}

The distinction of knowing that and knowing how in contemporary epistemology traces back to Gilbert Ryle (Ryle 1971). One can distinguish roughly knowing that from knowing how by a distinction 
of the domains of the operations: the first is knowledge of propositions whereas the second is knowledge of something other than propositions. So, e.g., we usually distinguish the mode of knowing that Hannah rides a bicycle, i.e. knowing the proposition 'Hannah rides a bicycle., from the mode of knowing how it is to ride a bicycle. Note that sometimes also such a distinction is made by distinguishing along the line of Bertrand Russell's proposal to differentiate between knowledge by description and knowledge by acquaintance (e.g., endnote 24, pp. 498f and p. 61: 'Knowledge by acquaintance as philosophers have discussed it is thus just one species of knowledge in the Franciscan mode.'). Note also that our distinction according to the domains of the operations is in fact very rough and is convincingly criticised, e.g., in (Fumerton 2008: sect. 1, par. 6-8). But for the purpose of our argumentation our coarse-grained distinction seems to be subtle enough.

It is natural to ask which relations hold between these two modes. Ryle for himself thinks that there is no relevant relation between them. He thinks especially that there is no - as, e.g., stipulated by the so-called intellectualist legend ('knowing-that is taken as the ideal model of all operations of intelligence', (see Ryle 1971: 215)) - relation of reduction between knowing that and knowing how. Ryle argues for this claim by trying to show that if knowing how could be reduced to knowing that, then knowledge about how things are wouldn't manifest ever and so there wouldn't exist any knowing how at all (for a short summary of Ryle's argumentation see Stanley \& Williamson 2001: 413). Contrary to Ryle's point of view there are two alternatives. One can claim in accordance with the intellectualist legend that knowing how is reducible to knowing that as, e.g., Jason Stanley and Timothy Williamson do. According to them the truth conditions for a sentence like 'Hannah knows how to ride a bicycle.' are expressible exactly by the truth condition of the sentence 'For some contextually relevant way $w$ for Hannah to ride a bicycle, Hannah knows that $w$ is a way for Hannah to ride a bicycle..' But one can also claim that the reduction goes the other way round by arguing for the thesis that knowing that is fully reducible to knowing how. Such a position is, e.g., expressed by Stephen Hetherington and is argued for by the claim that knowing that is commonly characterized as justified true belief and that in being justified in a proposition, one also knows how to apply correctly the reasons for believing in that proposition (Hetherington 2008: 316). Also along this line of argumentation, Hilary Putnam claims that "knowing the meaning of the word "gold" or of the 
word "elm" is not a matter of knowing that at all, but a matter of knowing how [to find experts]' (Putnam 1996: xvi).

Stump agrees with the position of Ryle, although she uses another line of argumentation. She thinks that the main difference between both modes of cognition lies in a different point of view. Whereas the mode of knowing that is much more detail oriented, technical, and by this sometimes narrow and restricted, the mode of knowing how is much more general and by this broad (see pp. 23, 27, 62). For distinguishing these modes she gives a prototypic and eponymous example: A Dominican wanted Francis to explain God's claim that if he (the Dominican) doesn't warn the wicked man about his wickedness, God will hold him (the Dominican) responsible for the wicked man's sins. The Dominican's interpretation of this claim was very straightforward and so he thought that he will be held responsible for many sins of many wicked men he hadn't instructed. In opposition to the narrow view of the Dominican, Francis' answer was much more generalizing. He proposed to interpret this claim as: 'a servant of God should be burning with life and holiness so brightly that by the light of example and the tongue of his conduct, he will rebuke all the wicked. In that way [... he] will proclaim their wickedness to all of them.' The example ends 'with the Dominican's going away very impressed' (pp. 44f). Our identification of the Franciscan mode of knowledge with knowledge how can be justified in the following way: the classical phenomena of knowing how as, e.g., 'knowledge of redness', 'knowing a colour' and more generally knowledge of 'various other first-person experiences' are according to Stump not reducible to knowledge that (cf. pp. 50f). Since she stipulates: 'I will call knowledge which cannot be reduced to knowledge that "Franciscan knowledge"; I will call the other, more philosophically ordinary kind of knowledge "Dominican knowledge"' (p. 51), the classical phenomena of knowing how is Franciscan knowledge.

According to this identification and the example about the Dominican and the Franciscan above, one can distinguish the Dominican mode of knowing that from the Franciscan mode of knowing how by distinguishing the way of interpreting a text. To adhere to the general distinction of knowing that from knowing how by a distinction of the domain of these operations, one may say that Francis' knowledge seems to be not about a single proposition, but about a whole text in some context, or yet more abstract about something intended by God, etc. The relevant part of this distinction is the fact that in the Dominican mode there was only 
one interpretation of the expression 'proclaim to the wicked man his wickedness', whereas in the Franciscan mode there were several such interpretations under consideration. Stump thinks that the Franciscan mode of knowing something - e.g., knowing how to warn the wicked man about his wickedness - is sometimes more adequate than the Dominican mode of knowing something - e.g., knowing that the wicked man has to be warned (whereby 'warned' is understood literally) about his wickedness - because the Franciscan mode is sometimes more appropriate than the Dominican mode by the fact that it is vague:

[...] in cases where necessary and sufficient conditions for something are hard to find or in the nature of things not available (for example, because what we are attempting to define is irreducibly vague), then Franciscan categorization or typology may in fact be more accurate, or at least more true to the phenomena, than Dominican categorization, which misrepresents the thing it seeks to describe. (Stump 2010: 47)

This fact can be illustrated in a simplified way by mapping the expression 'proclaim to the wicked man his wickedness' Dominicanly to the order Tell the wicked man that he is wicked! and Franciscanly to the, e.g., three orders Tell the wicked man that he is wicked!, Burn with life and holiness so brightly that by the light of example and the tongue of conduct you rebuke all the wicked! (p. 44) and, e.g., Show the wicked man that he is wicked by your exemplary life and awake the desire in him to change his wicked life! which is to state that 'proclaim to the wicked man his wickedness' is vague (note that by an illustration with such a mapping vagueness is understood in the sense of an 'ambiguity on a grand and systematic scale' (Fine 1975: 282)). Under the assumption that someone who burns with life and holiness very brightly and who does not tell the wicked man that he is wicked is nevertheless not responsible for the wicked man's sins, the Dominican interpretation is false or inaccurate whereas the Franciscan interpretation is more accurate inasmuch as it is true in two out of three cases.

This distinction of knowing that and knowing how is not complete, because there seem to be some other relevant forms of knowing how than those acquired by (vague) re-interpretation. Stump says that she is 'not able to say what all these cases [of irreducible Franciscan knowledge] have in common' (p. 47). But since the third part of her book is a reinterpretation of biblical stories, this distinction of knowing that and 
knowing how or knowing by narratives seem to be one of the most relevant ones for Stump's defence.

Sometimes, as, e.g., in Stump's argumentation, it is also useful or necessary to speak about the fact that someone knows some person. Since persons are not propositions, this mode of knowing is - according to the given basic criterion for a distinction - also a mode of knowing how and by this Franciscan knowledge. So, in Stump's view, also for this mode of knowledge holds what was said above: to know a person is not reducible to knowing some propositions about this person. More precisely speaking, the claim that Hannah knows Paula, e.g., cannot be reduced to some claim of the sort: Hannah knows that Paula has black hair, that she is a student, that she is in love with Jerome, etc. To give such an interpretation of 'Hannah knows Paula.' would be too narrow and would be thinking in the Dominican mode. Also knowing other things like countries - e.g., knowing China - is not reducible to a set of claims about the countries (cf. Stump 2010: 373f), which, again, would be knowledge in the Dominican mode. According to Stump there is something missing in that mode, and that there is something missing is not due to the fact that in the Dominican mode a list of propositions about Paula or China will always be incomplete. The difference appears according to her because, e.g., knowing a person includes also having some second-person and not only a third-person experience with that person (cf. p. 56). So, in order to understand that someone knows a person it is necessary to get second-person experience with that person. And here the role of narratives come into play. According to Stump, second person experience 'can be made available to others who lack the second-person experiences in question by means of a story that represents the experience' (p. 81).

What is true of cognition is, in Stump's view, also true of desires and wishes and so one can also distinguish two different optative modes, a Dominican mode of desiring that and a Franciscan mode of desiring how, e.g., desiring a person (cf. p. 57). The cognitive and the optative mode are according to her fully available only in the Franciscan mode and so an adequate understanding of a person's knowing how and desiring how is possible not by arguments (alone), but by a consideration of stories. 


\section{STUMP'S RECONSTRUCTION OF THE AQUINEAN DEFENCE}

Stump aims with her book to give a solution to the problem of suffering by providing a framework for designing a possible world wherein for every suffering of a mentally fully functional adult human being there is a morally sufficient reason for God to allow this suffering which is to allow the undermining of a person's flourishing or to allow the depriving of her desires of the heart (cf. pp. 4, 8). The possible world she characterizes is the one designed by Thomas Aquinas.

Preliminary to the defence is Aquinas' theory of love, which will be sketched first: there are, according to Aquinas, two necessary conditions for some $x$ in order for that $x$ to be in love with some $y$ (cf. p. 91):

- $x$ desires the (objectively) good for $y$, and

$-x$ desires union with $y$

Furthermore, there are two necessary conditions for $x$ 's being in union with $y$, namely personal presence and mutual closeness (cf. p. 109). And there are again two necessary conditions for $y$ 's being personally present to $x$, namely: $x$ has second-person experience with $y$, and $x$ and $y$ have shared attention, where shared attention is the common triadic relation (of triangulation): $x$ and $y$ join attention ('are meeting in minds') with respect to some entity $z$ (cf. pp. 112f). Stump also gives a necessary condition for mutual closeness between $x$ and $y$ : 'A person alienated from himself cannot have someone else close to him.' (p. 125) So, a necessary condition for being in mutual closeness with someone is to be personally integrated. Personal integration is defined in an expanded Frankfurtean sense: the desires of a person $x$ can be distinguished according to the iteration of the operation of desiring within the desires. Let's call the operation of desiring ' $D_{\mathrm{x}}$ '. Then, e.g., $x$ 's desiring of a proposition $p$, i.e. $D_{x} p$, is a first-order desire, whereas, e.g., $x$ 's desiring of desiring $p$, i.e. $D_{x} D_{x} p$, is a second-order desire (cf. p. 138). According to Stump, a person $x$ lacks personal integration iff at least one of the following two conditions is satisfied (cf. p. 139):

- there is some $p$ such that $x$ desires $p$ and $x$ desires $\sim p$ on the same level, i.e. e.g., $D_{\mathrm{x}} p \ll D_{\mathrm{x}} \sim p$, or

- there is some $p$ such that $p$ is objectively wrong and $x$ desires $p$, i.e. $D_{x} p$ where $p$ is objectively wrong Aquinas, so Stump, thinks that an anthropic property of a human's web of desire is that every person has a will 'which is strong enough to enable him to form the first-order volition to ask God to strengthen his will' (p. 159), 
so it holds for every person $x$ that it's possible for her to generate $D_{x} D_{x} p$, where $p$ represents 'God helps $x$ '.

With this preliminary claims about love at hand, we can now sketch the Aquinean theory of functional suffering, i.e. Stump's defence! According to the given theory of love, a person $x$ loves God only in case that $x$ desires the objectively good for God (which is according to Stump, since God does not lack any good, to desire what God desires as good cf. p. 101) and $x$ desires union with God. By the definitions given above, union with God can be thought of as 'meeting in mind' with God in a situation of triangulation. For being able to get united with God in such a situation, it is, as sketched above, necessary to be personally integrated. And exactly here, so Stump says, the morally sufficient reason of God's allowing suffering has to be sought: since union is a necessary condition for loving God and since personal integration is a necessary condition for union, God may allow suffering in order to support personal integration (some scientific investigations show that sometimes a person's suffering can enable her to grow in psychic integration, e.g., in the situation of posttraumatic growth - cf. p. 458). Since personal integration is of so much importance in loving God, it's natural to give the following scale of values (cf. p. 387):

$(-)$ fragmentation $<$ partly fragmentation $<\ldots<$ partly integration $<$ full integration/glory $(+)$

On Aquinas' view, it is fair (morally sufficiently reasonable) only to allow suffering in one of the following two situations:

- Case M1: suffering involuntarily simpliciter suffering $_{1}$ is necessary to avoid suffering ${ }_{2}$ whereby $\mid$ suffering $_{1}|<|$ suffering $_{2} \mid$

- Case M2: suffering secundum quid (without giving up one's heart desires - cf. p. 383)

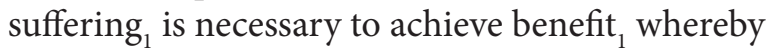
$\mid$ suffering $_{1}|<|$ benefit $_{1} \mid$

Since absolute fragmentation (the worst thing, i.e. hell - cf. p. 404) is very negative, according to $\mathrm{M} 1$ it is morally sufficiently reasonable for God to allow suffering to some extent for the avoidance of absolute fragmentation. And since full personal integration or glory is very positive (cf. p. 404), according to M2 it is morally sufficiently reasonable for God to allow - of course only in full accordance with the 'real desires' of the sufferer - suffering for glorification in such model situations to some extent also. 
This is a very brief sketch of the general framework wherein discussions of the problem of suffering should be embedded according to Aquinas and Stump. In the next section we are going to indicate how Stump embeds in this framework the discussion of the suffering of Job, Samson, Abraham and Mary of Bethany. We will then try to show that the result of her embedding is an understanding of that suffering in the Dominican mode.

\section{A MARRIAGE OF THE TWO APPROACHES}

Stump has established the methodology of her investigation in the first part of the book. In the second part she established Aquinas' theory of love. In the third part she considered some biblical stories on the suffering of the four biblical characters Job, Samson, Abraham and Mary of Bethany. And in the final part she established her defence. According to her own evaluation, the first two parts are in the Dominican mode, the third part is in the Franciscan mode and in the fourth part she tries 'to marry the two approaches' (p. 63). My aim here is to show that the marriage is very one-sided and that it is Dominic who is on the mighty side.

The problem of suffering in the discussion of the biblical stories of the four mentioned characters may be described as follows: Job is a good man, cares about his family, is responsible with his holdings, and praises God. Nevertheless God allows that misery comes upon him. So we naturally ask why God allows this and what the morally sufficient reason for letting Job suffer could be. At first glance, i.e. from a Dominican perspective, we are not able to find such a reason because the 'real desires' of Job are not visible to us. We don't know, e.g., whether $D_{\mathrm{Job}} p$ - where $p$ represents ' Job has the most extensive and powerful conversation with God. - or not. But by taking a Franciscan perspective, i.e. by widening the ways of interpreting the story, we may come to an affirmative answer to the question. And by applying model M2 (suffering in order to achieve a great benefit), we may be satisfied in finding a morally sufficient reason for God's allowing the suffering of Job.

In a similar way one may posit a problem with the stories of Samson, Abraham, and Mary, then reconsider their stories, after that apply the models of functional suffering, and finally end up with the following results (cf. pp. 401f):

- Sanctification (M2): 'Job begins by losing all that apparently constitutes flourishing in his society. But at the end of his story 
God comes to talk to him face to face in the most extensive and powerful conversation.'

- Sanctification (M2): 'Abraham [...] has struggled his way to a deep trust in God that makes him a father of faith.'

- Sanctification (M2): 'Mary is heartbroken when her beloved brother dies [...] but at the end of her story she has come closer to Jesus than even the apostle on whom Jesus founds his church [which is indicated by the feet washing scene].'

- Justification (M1): 'Samson's [...] suffering is justified in virtue of its contribution to warding off for Samson the worst thing for human beings.'

- Sanctification (M2): 'Because Samson reacts passionately [...], his suffering also contributes to making him glorious.'

As one can clearly see, for embedding the discussions of the various sufferings one always has to switch into the Dominican mode. Only a clear (non-vague) understanding of the desires of the different persons $\left(D_{\text {Abraham }} p\right.$, where $p$ represents 'Abraham is the father of faith.', etc.) allows one to find a morally sufficient reason for each suffering. Think on the example of proclaiming the wicked man his wickedness! By Franciscan knowledge one may get several possible interpretations of some expressions. But for understanding what to do, one has to make a decision for a specific interpretation. Something similar holds also for the defence: in order to embed discussions of suffering into the framework provided by Aquinas and Stump, one also has to make a decision for a specific interpretation. It seems to me obvious that the application of the defence (which is to embed the discussion into the provided framework) starts from a clear and non-vague description of the problematic situation under consideration. Similar observations can be made in general in discussions where one uses narratives or a parable for illustrating relations of analogy: in such a discussion people usually ask for a more detailed description until they end up with an exact non-vague description of the similarities. And that is to end up with knowledge in a Dominican and not a Franciscan mode.

The only part where Franciscan empathy seems to be of relevance with respect to the provided defence is not in the application of Aquinas' and Stump's general framework to the single stories, but in a reconsideration and preparation of the stories. Although the, by Stump re-told, stories of Job, Samson, Abraham and Mary of Bethany may be accepted as adequate reformulations by many philosophers of religion, 
etc., an argumentation for the adequacy of such reformulations and preparations seems to be very incomplete, prone to problems and by this excluded from an elaborated defence. So, regarding the acquirement of knowledge or beliefs, both modes may be adequate, but regarding justification of one's beliefs, only the Dominican mode seems to be adequate (cf. for this claim also the usual distinction of methods in the philosophy of science between methods within the context of discovery and methods within the context of justification). Let me make this point more clear by summing up the argumentation:

(1) One may distinguish, as Stump does, two modes of knowledge, namely Dominican and Franciscan knowledge.

(2) Dominican knowledge is characterized as propositional knowledge (knowing that). Franciscan knowledge is characterized as non-propositional knowledge (knowing how).

(3) One - for the defence very relevant - kind of non-propositional knowledge is knowledge by narratives, that is, e.g., not only having in mind a very detailed description of the situation of Job's suffering, but taking also a more general and vague point of view about his suffering (which can be expressed technically as ambiguous mapping of descriptions to situations, facts or orders).

(4) The defence of Aquinas and Stump is applicable only in case of a non-vague or non-ambiguous description of a situation of suffering.

(5) Hence, the defence is applicable only in the Dominican mode. Because of this reason I think that the 'convincing power' of Franciscan story telling may be doubted.

Acknowledgement. This publication was made possible through the generous support of a grant from the John Templeton Foundation, grant \#15571 ("Analytic Theology").

\section{BIBLIOGRAPHY}

Fine, Kit. 1975. 'Vagueness, Truth and Logic', Synthese, 30.3/4: 265-300.

Fumerton, Richard. 2008. 'Knowledge by Acquaintance vs. Description', The Stanford Encyclopedia of Philosophy (Winter 2010 Edition). Ed. by Edward N. Zalta. URL: <http://plato.stanford.edu/archives/win2010/entries/knowledgeacquaindescrip/> [accessed 12/09/2012] 
Hetherington, Stephen. 2008. 'Knowing-That, Knowing-How, and Knowing Philosophically', Grazer Philosophische Studien, 77.1: 307-324

Putnam, Hilary. 1996. 'Introduction', in The Twin Earth Chronicles: Twenty Years of Reflection on Hilary Putnam's "the Meaning of 'Meaning", Ed. by Andrew Pessin and Sanford Goldberg (New York: M. E. Sharpe), pp. xv-xxii

Ryle, Gilbert. 1971. 'Knowing How and Knowing That', in Collected Papers, Ed. by Gilbert Ryle (New York: Barnes and Nobles), pp. 212-225

Stanley, Jason and Timothy Williamson. 2001. 'Knowing How', The Journal of Philosophy, 98.8: 411-444

Stump, Eleonore. 2010. Wandering in Darkness: Narrative and the Problem of Suffering (Oxford: Clarendon Press) 